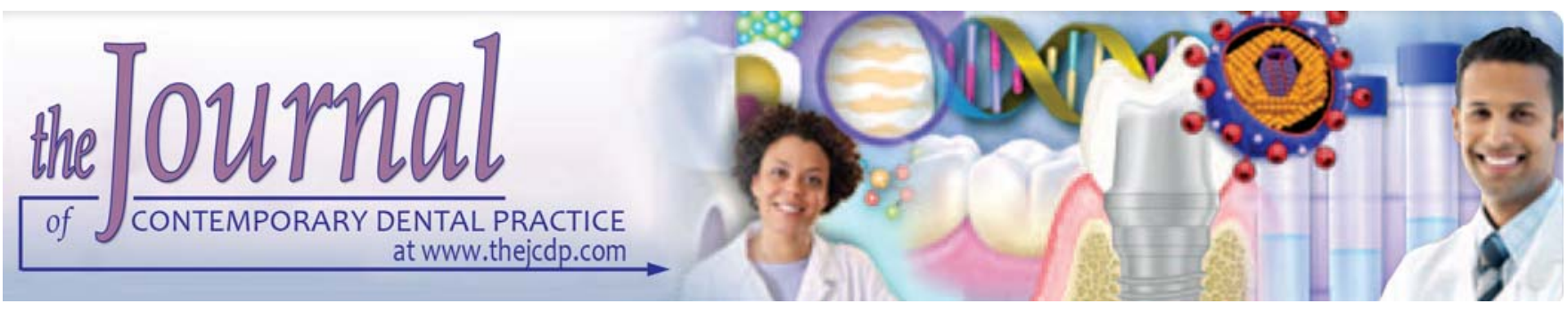

\title{
Comparative Study of the Antimicrobial Effect of Three Irrigant Solutions (Chlorhexidine, Sodium Hypochlorite and Chlorhexidinated MUMS)
}

\author{
Maryam Bidar, Sepideh Hooshiar, Mahboubeh Naderinasab, Mostafa Moazzami, Hossein Orafaee \\ Neda Naghavi, Hamid Jafarzadeh
}

\section{ABSTRACT}

Aim: To compare the antimicrobial effect of $2 \%$ chlorhexidine, $2.5 \%$ sodium hypochlorite and MUMS containing $2 \%$ chlorhexidine.

Materials and methods: All of the above irrigants were examined on Enterococcus faecalis, Streptococcus mutans, Candida albicans, Lactobacillus casei and E.coli. A total of 0.5 CC of each solution and $0.5 \mathrm{CC}$ of M CF arland solution bacterium were added to each examination tube. After 15, 30 and 45 minutes, colony count was performed for each tube. The difference in the number of bacteria indicated the effect taken by disinfectant material.

Results: MUMS containing chlorhexidine showed the antimicrobial properties just like chlorhexidine's effect against E.coli, Streptococcus mutans, Candida albicans, Enterococcus faecalis and Lactobacillus casei in preventing these entire microorganisms to incubate. Sodium hypochlorite was not effective against $E$ nterococcus faecalis and $C$ andida albicans incubated in 15, 30 and 45 minutes and Enterococcus faecalis in 15 minutes.

Conclusion: MUMS has antimicrobial properties similar to chlorhexidine.

Clinical significance: As MUMS containing chlorhexidine can transfer chlorhexidine through its own surfactant around apical area and it can open the dentinal tubules by its own chelator for more penetration of chlorhexidine, it may be a choice for canal irrigation.

Keywords: Antimicrobial activity, Irrigant, Chlorhexidine, Sodium hypochlorite, Microbial study.

How to cite this article: Bidar M, Hooshiar S, Naderinasab M, Moazzami M, Orafaee $H$, Naghavi $N$, Jafarzadeh $H$. Comparative Study of the Antimicrobial Effect of Three Irrigant Solutions (Chlorhexidine, Sodium Hypochlorite and Chlorhexidinated MUMS). J Contemp Dent Pract 2012;13(4): 436-439.

\section{Source of support: Nil}

Conflict of interest: None declared

\section{INTRODUCTION}

The role of microorganisms in the pathogenesis of pulp and periradicular diseases has been established. ${ }^{1,2}$ The purpose of root canal preparation is removing microorganisms from the canal by using biomechanical procedures accompanied with the use of antimicrobial agents. For decades, investigators have searched for antimicrobial agents that are more effective in debridement of the root canal system. ${ }^{3-7}$

A $n$ ideal irrigant should be an effective germicide and fungicide, be nonirritating to the periapical tissues, remain stable in solution, have a prolonged antimicrobial effect, be active in the presence of blood, serum and protein derivates of tissue, have low surface tension, not interfere with repair of periapical tissues, not stain tooth structure, be able to completely remove the smear layer, be able to disinfect the underlying dentin and its tubules and be relatively inexpensive. However, the common regimens in chemomechanical procedures using instrumentation and irrigation are not predictably effective in canal disinfection. 8,9

Sodium hypochlorite $(\mathrm{NaOCl})$ is the most common endodontic irrigant used. It presents strong antimicrobial activity and ability to dissolve necrotic pulpal tissue, so is usually chosen as a suitable canal irrigant. However, it is cytotoxic when it contacts periapical tissues. ${ }^{10}$

Chlorhexidine $(\mathrm{CHX})$ is another antimicrobial agent that has been advocated for disinfection of the root canal system. ${ }^{5}$ At low concentrations, it is bacteriostatic whereas at higher concentrations, it will cause the coagulation and precipitation of cytoplasm and therefore is bactericidal. ${ }^{11}$

MUMS is a newly-developed irrigant that contains chelating agent and surfactant. Its chelator is ethylene diamine tetraacetic acid (EDTA) and surfactants are polyoxyethylene sorbitan monooleate (Tween 80 ) and 
sorbitan monooleate (Span 80). T ween 80 and Span 80 are generally regarded as nontoxic and nonirritating. MUM S changes the surface tension and so may be effective in delivering irrigant to the apical portion of the canal. The combination of $\mathrm{CHX}$ with MUMS may help in both antibacterial effects of $\mathrm{CHX}$ and smear layer removal of EDTA. On the other hand, it may block $\mathrm{CHX}$ from adhering to the root surface.

The purpose of this study was to compare the antimicrobial effect of $2 \% \mathrm{CHX}, 2.5 \% \mathrm{NaOCI}$ and $\mathrm{MUMS}$ containing $2 \% \mathrm{CHX}$ on specific, most commonly associated microorganisms found within infected root canal over different time periods.

\section{MATERIALS AND METHODS}

Bacteria used in this study were Streptococcus mutans (A TCC 35668), Lactobacillus casei (A TCC 393), Candida albicans, E.coli and Enterococcus faecalis isolated from patients. The bacteria inoculated in blood agar for 3 days at $35^{\circ} \mathrm{C}$. A fter growing colonies, a smear was prepared from each petri and gram stained to confirm the presence of a single strain.

Four to five colonies of each bacterium from blood agar plates were solved in brain heart infusion ( $\mathrm{BHI}$ ) broth and incubated for 1 to 2 hours at $35^{\circ} \mathrm{C}$ until the bacteria reach the logarithmic growth phase and the number of microorganisms increase. $B$ acterial cells were resuspended in saline to give a final concentration of about $1.5 \times 10^{8} \mathrm{cells} / \mathrm{ml}$, adjusted to $0.5 \mathrm{M} \mathrm{cF}$ arland turbidity standards.

In one sterile glass tube, $0.5 \mathrm{ml}$ of $2.5 \% \mathrm{NaOCl}$ and $0.5 \mathrm{ml}$ of E.coli's broth were mixed and incubated after 15,30 and 45 minutes in blood agar. This was performed for each microorganisms and each irrigants separately and repeated for 3 times. Colony forming units (CFU) were determined for each sample after 24 to 48 hours of incubation at $37^{\circ} \mathrm{C}$.

$\mathrm{K}$ olmogorov-Smirnov test was used for assessment of the normality of samples distribution. $M$ an-W hitney test was used to compare the irrigants in three different times while critical level of significance was set at $<0.05$.

\section{RESULTS}

The effect of each irrigants on each microorganism in each period has been shown in Table 1. There were significant differences between 15 minutes ( $\mathrm{T} 1$ ) and 30 minutes ( $\mathrm{T} 2$ ) in CFU (T1 $p=0.000$ and T $2 p=0.014$ ).

Kolmogorov-Smirnov test showed that dates' distributions were not normal so M an-W hitney test was used to compare the irrigants in different times. This test showed that in the significance level of $5 \%$, there was no significant difference between $\mathrm{CHX}$ and MUMS in T1 and T2 $(p=$ 1.0) but the differences between MUMS containing $\mathrm{CHX}$ with $\mathrm{NaOC}$ in $\mathrm{T} 1$ were significant $(p=0.029$ and $p=0.029$, respectively; Table 2).

In comparison of CFU of each irrigants in three different times, results showed that there was significant difference only in $\mathrm{NaOCl}$ group $(p=0.001$ ). This test was not usable in two other groups of irrigants because the colony numbers were zero.

In $\mathrm{NaOCl}$ group, there were significant differences between $T 1$ and $T 2(p=0.017)$ and between $T 1$ and T3. In $T 1$, Enterococcus faecalis, Candida albicans and E.coli could grow. In T2, Enterococcus faecalis was not obvious and the colony numbers of Candida albicans and E.coli reduced. In $\mathrm{T} 3$, the only colonies seen were Candida albicans.

\section{DISCUSSION}

Elimination of bacteria from the root canal system is essential for long-term success of endodontic treatment. ${ }^{12}$ For this purpose, $\mathrm{CHX}$ has been shown to be effective against Enterococcus faecalis in vitro, ${ }^{13}$ so it has been recommended for root canal disinfection. ${ }^{5}$ Because of its inability to dissolve pulpal tissues, its use might be limited to a final rinse to enhance root canal disinfection. The $\mathrm{pH}$ of $\mathrm{CHX}$ is 5.5, and although the addition of citric acid and Tween 80 lowers its $\mathrm{pH}$ to 2.2, no significant difference in its ability to kill Enterococcus faecalis has been noted. ${ }^{14}$ In the present study, there were no significant difference in antimicrobial effect of $\mathrm{CHX}$ and M UM S containing $\mathrm{CHX}$.

$\mathrm{NaOCl}$ is the most commonly used antimicrobial irrigant in endodontics. This material has some advantages such as antimicrobial activity, tissue dissolving ability, lack of tooth discoloration and availability. A primary concern for the use of this chemical agent as a canal irrigant is its toxicity and potential for severe inflammatory response in the periradicular tissues. ${ }^{15,16}$

\begin{tabular}{|c|c|c|c|c|c|c|c|c|c|c|c|c|c|c|}
\hline \multirow[t]{2}{*}{ Irrigant } & \multicolumn{3}{|c|}{ Streptococcus mutans } & \multicolumn{3}{|c|}{ Lactobacillus casei } & \multicolumn{3}{|c|}{ Candida albicans } & \multicolumn{3}{|c|}{ Escherichia coli } & \multicolumn{2}{|c|}{ Enterococcus faecalis } \\
\hline & $15 \mathrm{mins}$ & ns 30 mins & 45 mins 1 & & ins 30 mins 4 & 45 mins & 15 mins & 30 mins & 45 mins & 15 mins & 30 mins & 45 mins & 15 mins 3 & mins 45 mins \\
\hline $2 \% \mathrm{CHX}$ & * & * & * & $*$ & $*$ & * & $*$ & * & $*$ & * & * & $*$ & * & * \\
\hline $2.5 \% \mathrm{NaOCl}$ & $*$ & $*$ & $*$ & $*$ & $*$ & $*$ & 27,000 & 3,333 & $*$ & 19,000 & 9,500 & $*$ & $1,00,000$ & $*$ \\
\hline MUMS with $\mathrm{CHX}$ & $*$ & $*$ & $*$ & $*$ & $*$ & $*$ & $*$ & $*$ & $*$ & $*$ & $*$ & $*$ & $*$ & $*$ \\
\hline
\end{tabular}

*No growth 
Table 2: Comparison of different irrigants in T1 and T2 with Mann-Whitney test

\begin{tabular}{llcll}
\hline Irrigant & Number & Mean & p-value \\
\hline T1 & $2 \% \mathrm{CHX}$ & 15 & 12 & 0.029 \\
& $2.5 \% \mathrm{NaOCL}$ & 15 & 19 & \\
$\mathrm{~T} 2$ & $2 \% \mathrm{CHX}$ & 15 & 13.5 & 0.217 \\
& $2.5 \% \mathrm{NaOCL}$ & 15 & 17.5 & \\
$\mathrm{~T} 1$ & $2 \% \mathrm{CHX}$ & 15 & 15.5 & 1.0 \\
& MUMS with CHX & 15 & 15.5 & \\
T2 & $2 \% \mathrm{CHX}$ & 15 & 15.5 & 1.0 \\
& MUMS with CHX & 15 & 15.5 & \\
T1 & $2.5 \% \mathrm{NaOCL}$ & 15 & 19 & 0.029 \\
& MUMS with CHX & 15 & 12 & \\
T2 & $2.5 \% \mathrm{NaOCL}$ & 15 & 17.5 & 0.217 \\
& MUMS with CHX & 15 & 13.5 & \\
\hline
\end{tabular}

The results of this study verified the effectiveness of $\mathrm{CHX}$ and MUMS containing $\mathrm{CHX}$ against bacteria and yeasts even in 15 minutes but in $\mathrm{NaOCl}$ group, no bacteria were killed in this time. In 30 minutes, no growth of Enterococcus faecalis observed with $\mathrm{NaOCl}$. In the study of $\mathrm{V}$ ianna et al ${ }^{17} 0.5$ and $1 \% \mathrm{NaOCl}$ required 30 and 20 minutes, respectively to completely kill Enterococcus faecalis and Candida albicans. Also, Radcliffe et al ${ }^{18}$ reported that $0.5 \% \mathrm{NaOCI}$ killed $\mathrm{Enter}$ ococcus faecalis only after 30 minutes of incubation. Waltimo et al ${ }^{19}$ showed that $0.5 \% \mathrm{NaOCl}$ killed Candida albicans in 30 seconds. However, when diluted further to $0.05 \%, \mathrm{NaOCl}$ did not kill Candida albicans even after 24 hours of incubation. Different results obtained in these studies can be related to the differences in the methods used and to the presence of confounding factors during the testing. The magnitude of the antimicrobial efficacy of a medicament can be influenced by the methodology, microbial characteristics in the biofilm, exposure time and concentration of the substance tested. ${ }^{20,21}$

$M$ any root canal irrigants have good antimicrobial activity in vitro whereas in vivo, they often fail to completely eradicate all microbes. Several factors can reduce the effectiveness of them in in vivo conditions, such as poor penetration of the irrigants to the apical portion of the canal, localization of microorganism in the canal and dentinal tubules, insufficient exposure time, low concentration and presence of organic and inorganic compounds in the canal..$^{22}$ Also, despite the presence of a controversy regarding the effect of the smear layer on the quality of instrumentation and obturation, the smear layer itself may be infected and may protect the bacteria al ready present in dentinal tubules. ${ }^{23}$ B ecause of these concerns, it may be necessary to remove the smear layer especially in infected root canals to allow penetration of disinfecting solution into the dentinal tubules in these teeth, so the irrigants can be able to penetrate all attribute of the canal.
To date, there is no single solution used in endodontics that simultaneously removes the smear layer and disinfects the entire root canal system except for M TA D. ${ }^{24,25}$ M U M S in combination with $\mathrm{CHX}$ may offer another solution with these properties. One significantfinding in the present study was the capacity of this solution to kill Enter ococcus faecalis after 15 minutes. This ability was not observed with $\mathrm{NaOCl}$.

A limitation of this in vitro study is that it does not account for the penetration ability of test irrigants in root canals. Other studies should be done to examine the efficacy of MUM containing $\mathrm{CHX}$ as a final rinse in disinfecting experimentally infected human root canals.

\section{CONCLUSION}

Chlorhexidinated MUMS has antimicrobial properties similar to chlorhexidine.

\section{CLINICAL SIGNIFICANCE}

As MUM S containing $\mathrm{CHX}$ can transfer $\mathrm{CHX}$ through its own surfactant around apical area and it can open the dentinal tubules by its own chelator for more penetration of $\mathrm{CHX}$, it may be a choice for canal irrigation.

\section{ACKNOWLEDGMENT}

This article is based on Sepideh H ooshiar's U ndergraduate thesis (N o. 2235). It has been supported in part by Dental Research Center and the Vice Chancellor for Research of Mashhad University of Medical Sciences, Mashhad, Iran.

\section{REFERENCES}

1. K akehashi S, Stanley HR, Fitzgerald RJ. The effects of surgical exposures of dental pulps in germ-free and conventional laboratory rats. O ral Surg 1965;20:340-49.

2. M öller AJR. Influence on periapical tissues of indigenous oral bacteria and necrotic pulp tissue in monkeys. Scand J D ent Res 1981;89:475-84.

3. L ee M T, B ird PS, W alsh LJ. Photo-activated disinfection of the root canal: A new role for lasers in endodontics. A ust Endod J 2004;30:93-98.

4. Perin FM , Franca SC, Silva-Sousa Y T, et al. Evaluation of the antimicrobial effect of Er:YAG laser irradiation versus $1 \%$ sodium hypochlorite irrigation for root canal disinfection. A ust Endod J 2004;30:20-22.

5. Zamany A, Safavi K, Spangberg LS. The effect of chlorhexidine as an endodontic disinfectant. Oral Surg Oral M ed Oral Pathol Oral Radiol Endod 2003;96:578-81.

6. Shabahang S, Pouresmail M, Torabinejad M. In vitro antimicrobial efficacy of MTAD and sodium hypochlorite. J Endod 2003;29:450-52.

7. Spoleti $P$, Siragusa M, Spoleti MJ. Bacteriological evaluation of passive ultrasonic activation. J Endod 2003;29:12-14. 
8. Bystram A, Sundqvist G. Bacteriologic evaluation of the efficacy of mechanical root canal instrumentation in endodontic therapy. Scand J Dent Res 1981;89:321-28.

9. M etzger $Z$, Basrani B, Goodid HE. Instruments, materials and devices. In: Hargreaves K M , Cohen S (Eds). Pathways of the pulp, 2011.

10. Marais JT. Cleaning efficacy of a new root canal irrigation solution: A preliminary evaluation. Int Endod J 2000;33:320-25.

11. Lin YH, M ickel AK, Chogle S. Effectiveness of selected material s against Enterococcus faecalis: Part 3. The antibacterial effect of calcium hydroxide and chlorhexidine on Enterococcus faecalis. J Endod 2003;29:565-66.

12. Haapasalo $M, \varnothing$ rstavik $D$. In vitro infection and disinfection of dentinal tubules. J Dent Res 1987;66:1375-79.

13. Lui J N, Sae-Lim V, Song K P, Chen N N. In vitro antimicrobial effect of chlorhexidine impregnated gutta percha points on Enterococcus faecal is. Int Endod J 2004;37:105-13.

14. Shabahang S, A slanyan J, Torabinejad M. The substitution of chlorhexidine for doxycycline in MTAD: The antibacterial efficacy against a strain of Enterococcus faecalis. J Endod 2008; 34:288-90.

15. Kavanagh CP, Taylor J. Inadvertent injection of sodium hypochlorite into the maxillary sinus. Br Dent J 1998;185: 336-37.

16. Neaverth EJ, Swindle R. A serious complication following the inadvertent injection of sodium hypochlorite outside the root canal system. Compendium 1990;11:474,476,478-81.

17. V ianna M E, Gomes BP, B erber VB, et al. In vitro evaluation of the antimicrobial activity of chlorhexidine and sodium hypochlorite. Oral Surg Oral M ed Oral Pathol Oral Radiol Endod 2004; $97: 79-84$

18. Radcliffe $C E$, Podtouridou $L, Q$ ureshi $R$, et al. Antimicrobial activity of varying concentrations of sodium hypochlorite on the endodontic microorganisms A ctinomyces israelii, A. naeslundii, Candida albicans and Enterococcus faecalis. Int Endod J 2004;37:438-46.

19. Waltimo TM , Orstavik D, Sire'n EK, et al. In vitro susceptibility of $C$ andida albicans to four disinfectants and their combination. Int Endod J 1999;32:421-29.

20. Spratt DA, Pratten J, Wilson M, Gulabivala K. An in vitro evaluation of the antimicrobial efficacy of irrigants on biofilms of root canal isolates. Int Endod J 2001;34:300-07.

21. Estrela C, Ribeiro RG, Estrela CRA, Pécora JD, Souza-N eto $M D$. A ntimicrobial effect of $2 \%$ sodium hypochlorite and $2 \%$ chlorhexidine tested by different methods. Braz Dent J 2003; 14:58-62.

22. Pappen FG, Qian W, Aleksejûniene J, L eonardo R de T, L eonardo M R, H aapasal o M. Inhibition of sodium hypochlorite antimicrobial activity in the presence of bovine serum albumin. J Endod 2010;36:268-71.
23. Torabinejad $M, H$ andysides $R, K$ hademi $A, B$ akland $L K$. Clinical implications of the smear layer in endodontics: $A$ review. Oral Surg Oral Med Oral Pathol Oral Radiol Endod 2002;94:658-66.

24. T orabinejad $M, K$ hademi A A, B abagoli J, et al. A new solution for the removal of the smear layer. J Endod 2003;29:170-75.

25. Torabinejad M, Cho Y, K hademi AA, Bakland LK, Shabahang $S$. The effect of various concentrations of sodium hypochlorite on the ability of MTAD to remove the smear layer. J Endod 2003;29:233-39.

\section{ABOUT THE AUTHORS}

\section{Maryam Bidar}

Dental Research Center, Faculty of Dentistry, M ashhad University of M edical Sciences, M ashhad, Iran

\section{Sepideh Hooshiar}

Dental Research Center, Faculty of Dentistry, M ashhad University of M edical Sciences, M ashhad, Iran

\section{Mahboubeh Naderinasab}

Department of M icrobiology, Imam Reza Hospital, M ashhad University of M edical Sciences, M ashhad, Iran

\section{Mostafa Moazzami}

Dental R esearch Center, Faculty of Dentistry, M ashhad University of M edical Sciences, M ashhad, Iran

\section{Hossein Orafaee}

Faculty of Pharmacology, M ashhad University of M edical Sciences M ashhad, I ran

\section{Neda Naghavi}

Dental R esearch Center, Faculty of Dentistry, M ashhad U niversity of M edical Sciences, M ashhad, Iran

\section{Hamid Jafarzadeh (Corresponding Author)}

Department of Endodontics, Dental Research Center, Faculty of Dentistry, M ashhad U niversity of M edical Sciences, Vakilabad Blvd, M ashhad, PO B ox: 91735-984, Iran, Phone: +98-511-8829501 Fax: +98-511-8829500, e-mail: hamid_j365@yahoo.com, JafarzadehB H@mums.ac.ir 